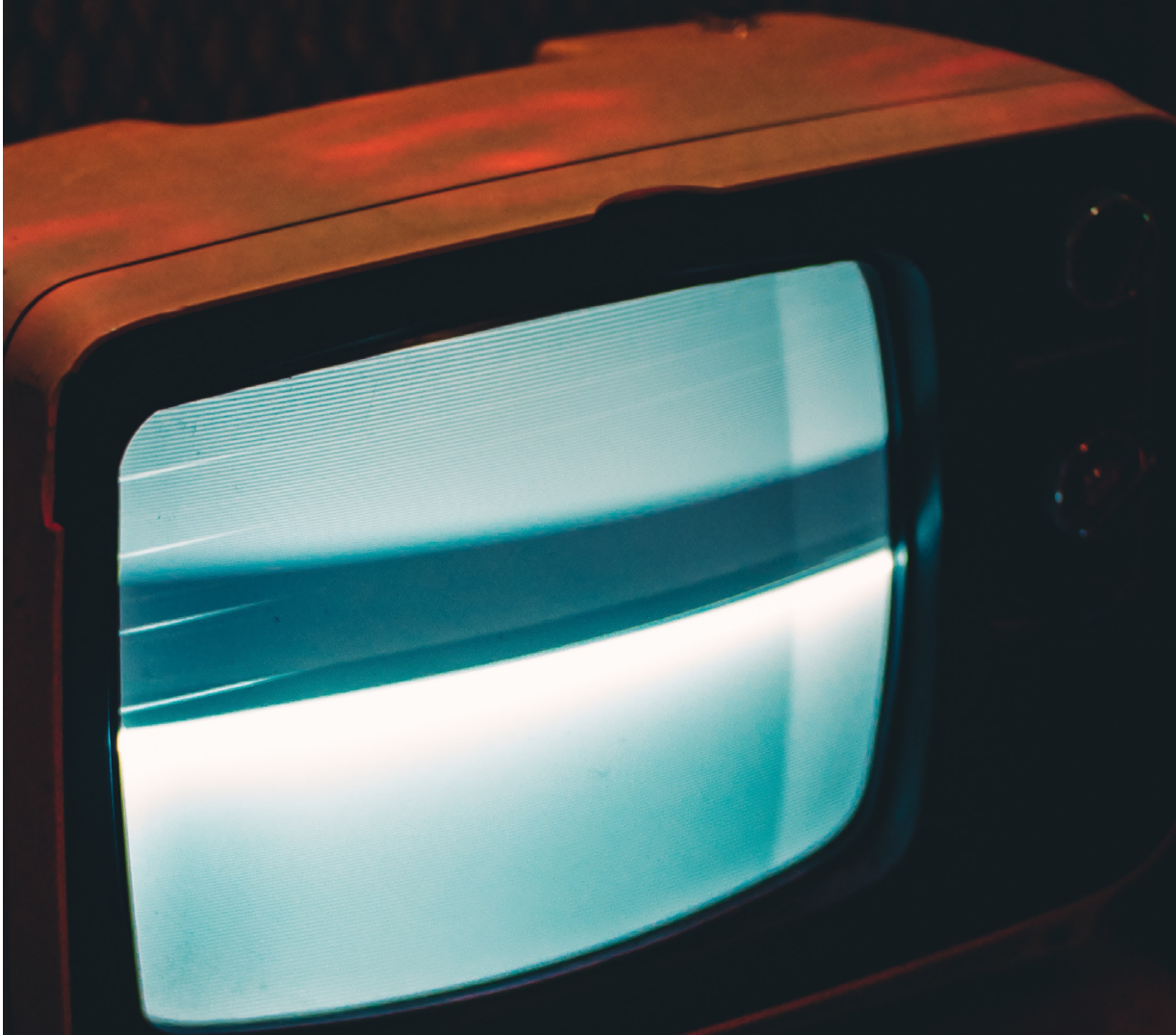

DOI: 10.5380/2238-0701.2021n22.10

Data de Recebimento: 21/04/2020

Data de Aprovação: 27/01/2021 
Os quadros como espaços de infotenimento: uma análise do JMTV $1^{a}$ edição 


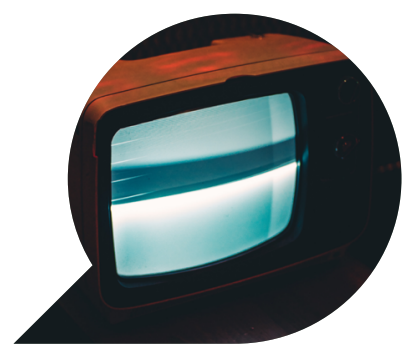

\title{
Os quadros como espaços de infotenimento: uma análise do JMTV $1^{\text {a }}$ edição
}

\author{
Pictures as spaces for infotainment: \\ an analysis of JMTV 1st edition
}

Las imágenes como espacios para el infoentretenimiento: un análisis de la 1a edición de JMTV

CAMILLA QUESADA TAVARES 1

FRIDA BÁRBARA LEITE MEDEIROS²

Resumo: $O$ ponto central desta pesquisa baseia-se em compreender como o infotenimento se apresenta nos quadros do telejornal JMTV $1^{\text {a }}$ edição, de Imperatriz, no Maranhão. O trabalho é embasado por conceitos de Gomes (2009; 2011), Dejavite (2006), Belém (2015; 2017) e discorre sobre as transformações e adaptações no telejornalismo para atender às exigências do público. Dentre essas alterações está o surgimento de um modelo híbrido, o infotenimento. Para atingir os objetivos propostos, foi realizada uma análise de

\footnotetext{
1 Professora adjunta da graduação e do Programa de Pós-Graduação em Comunicação da Universidade Federal do Maranhão (UFMA/Imperatriz). Doutora em Comunicação pela Universidade Federal Fluminense (UFF), mestre em Ciências Sociais Aplicadas pela Universidade Estadual de Ponta Grossa (UEPG) e graduada em Comunicação Social - Jornalismo pela mesma instituição. Coordenadora do grupo de pesquisa Comunicação, Política e Sociedade (COPS/UFMA). Editora da Revista Contracampo (PPGCOM/UFF). Desenvolve pesquisas sobre a atuação profissional, crise do jornalismo, cobertura jornalística e comunicação política, com perspectiva regional e de gênero. 2 Mestranda do Programa de Pós-Graduação em Comunicação da Universidade Federal do Maranhão, campus Imperatriz (UFMA/Imperatriz). Graduada em Comunicação Social - Jornalismo pela mesma instituição. Integrante do grupo de pesquisa Comunicação, Política e Sociedade (COPS).
} 
conteúdo quantitativa de 151 edições dos quadros fixos do JMTV exibidos em 2018, que correspondem ao corpus da pesquisa. À vista disso, argumentamos que os quadros são espaços de excelência para que determinadas temáticas sejam discutidas com mais profundidade em relação aos VTs factuais.

Palavras-chave: Quadros televisivos; Infotenimento; Telejornalismo; JMTV $1^{\text {a }}$ edição.

Abstract: The central point of this research is to understand how the Brazilian broadcast JMTV 1 edition, from Imperatriz, Maranhão, presented the infotainment on a specific television format. The work is based on concepts by Gomes (2009), Dejavite (2006), Belém (2015; 2017) and discusses the transformations and adaptations in telejournalism to attend to the demands of the public. Among these changes is the emergence of a hybrid model called infotainment. To achieve the proposed objectives, a quantitative content analysis was used to collect 151 editions of the JMTV fixed formats in 2018. This corresponds to the corpus of the research. Because of this, we argue that these fixed spaces are spaces of excellence so that certain themes are discussed in more depth concerning to the factual VTs.

Keywords: Television format; Infotainment; Telejournalism; JMTV 1st edition.

Resumen: El punto central de esta encuesta se basa en entender cómo el infotenimiento se presenta en los cuadros fijos del periodismo televisivo llamado JMTV 1 edición, desde Imperatriz, en Maranhão. El trabajo se basa en conceptos de Gomes (2009), Dejavite (2006), Belém (2015; 2017) y discurre sobre las transformaciones y adaptaciones en el teleperiodismo para satisfacer las exigencias del público. Entre estos cambios está la aparición de un modelo híbrido, el infotenimiento. Para alcanzar los objetivos propuestos, se realizó un análisis de contenido cuantitativo de 151 ediciones de los cuadros fijos del JMTV exhibidos en 2018, que corresponden al corpus de la investigación. Por lo tanto, argumentamos que los cuadros son espacios de excelencia para que determinadas temáticas sean discutidas con más profundidad en relación con los vídeos factuales.

Palabras-clave: Cuadros fijos; Infoentretenimiento; periodismo televisivo; JMTV $1^{\text {a }}$ edición. 


\section{Introdução}

A televisão é a principal fonte de informação e entretenimento presente nos lares brasileiros. De acordo com a TIC Domicílios 2019, 96\% das casas brasileiras possuem o aparelho, e o hábito de assistir à programação televisiva se espalhou ao longo dos anos. Nessa perspectiva, o telejornal, espaço central de conteúdo jornalístico da TV, constitui-se como uma das principais fontes de informação do brasileiro. É por ele que o cidadão tem acesso às principais informações do dia. Por isso, o telejornal representa um "lugar" de referência no cotidiano, assim como o espaço ocupado pela família, pelos amigos, pela escola e pela religião (VIZEU; CORREIA, 2008).

Desde seu surgimento até os dias atuais, o telejornalismo passou por diversas modificações para se adequar às novas tecnologias e exigências do público. A dinâmica dos telejornais vem alterando tanto o formato da notícia, como a linguagem e a forma como determinados assuntos são pautados na programação. Para Silva (2014), essas reformulações permitiram que a televisão passasse a informar o público de maneira mais atrativa, fazendo uso de recursos técnicos e textos leves.

Nesta lógica, com as mudanças tecnológicas e a possibilidade de acesso a conteúdos por diferentes plataformas, os telejornais do estado do Maranhão, dentre eles, o JMTV $1^{a}$ edição $^{3}$ (da TV Mirante, afiliada à Rede Globo), vêm modificando as formas de apresentação das notícias na tentativa de manter uma relação de informalidade e proximidade com a audiência. Assim, novos formatos foram surgindo e sendo incorporados na produção do noticiário, como, por exemplo, os quadros. Neste trabalho, entendemos que esse formato se caracteriza como uma estratégia dos telejornais por apresentar discussões ampliadas sobre determinados conteúdos exibidos numa reportagem, com uma linguagem ainda menos rígida e até de caráter opinativo. Esse formato híbrido, independente do suporte em que é veiculado, é classificado pela literatura como infotenimento (DEJAVITE, 2006; BELÉM, 2017).

Neste sentido, a presente pesquisa baseia-se no seguinte questionamento: como o infotenimento aparece nos quadros do telejornal JMTV $1^{a}$ Edição? Para isso, analisamos os três quadros fixos do JMTV

3 A emissora passou por um processo de reformulação dos telejornais em data posterior ao período de análise deste trabalho e, atualmente, o noticiário chama-se JM1. 
- Fica a Dica, Meu Bebê e Vida Saudável -, com o objetivo de perceber quais são as características e marcas do infotenimento nos conteúdos deste formato. A pesquisa busca ainda compreender como esse fenômeno, que está reconfigurando as práticas jornalísticas, se apresenta no telejornal regional.

Como justificativa para a realização desta pesquisa verificou-se que os quadros, apesar de fazerem parte das grades dos telejornais há décadas e ocuparem um espaço significativo na programação, são pouco pesquisados na academia. Outro fator a ser considerado é que, apesar de existirem outros trabalhos relacionados ao infotenimento no país (BELÉM, 2015, 2017; DEJAVITE, 2006; GOMES, 2009), os noticiários televisivos maranhenses ainda não foram pesquisados sob essa perspectiva. Para atender os objetivos propostos nesta pesquisa, será utilizado o método de pesquisa bibliográfica e a análise de conteúdo quantitativa, de acordo com Bardin (2006). A análise do telejornal é baseada no livro de códigos elaborado pela autora que define os seguintes critérios de observação: presença de personagens e especialistas, temática, linguagem, condução e técnica.

O texto segue divido em mais cinco partes: o tópico 2 é dedicado à discussão teórica que alicerça o estudo, debatendo particularmente o desenvolvimento do telejornalismo no Brasil e a hibridização de gêneros e formatos, que leva ao que a literatura caracteriza como infotenimento. O tópico 3 apresenta o espaço que os quadros têm na estrutura do telejornal escolhido para análise, o JMTV $1^{a}$ Edição; a quarta seção é reservada à apresentação metodológica e, em seguida, tem-se a análise dos resultados empíricos. Por fim, na sexta parte debateremos os principais resultados da pesquisa.

\section{Telejornalismo no Brasil: adaptações temáticas, hibridi- zação e o infotenimento}

A programação televisiva passou por diversos avanços técnicos, como as câmeras portáteis, que possibilitaram maior mobilidade dos apresentadores; registros e exibição das imagens de maneira imediata; e maior "conversação" entre imagem e texto - tudo isso com o objetivo de buscar caminhos que conquistem o público e o mantenha fiel 
à sua programação, apesar da concorrência de outras mídias, como a internet (SOUZA; PIVETA, 2011). Conforme Pereira (2010), com os avanços tecnológicos e as mudanças sociais permanentes, o jornalismo se reinventa para se adaptar às exigências da sociedade. Com isso, mudam-se as formas de produção, circulação e consumo das notícias, o perfil do jornalista e as corporações midiáticas. Becker (2016, p. 95) destaca que a reafirmação da televisão e do telejornalismo se dá por meio de estratégias narrativas menos rígidas, da incorporação de processos editoriais menos rigorosos e na adoção de outros gêneros, como o entretenimento.

O envolvimento sociocultural dos telespectadores, e os laços que criaram com a TV, surgiu do modo como a experiência da transmissão e da produção televisiva foi estrategicamente estabelecida. Coutinho (2009) acrescenta que os telejornais criam laços de pertencimento com um público e, a partir do enredo apresentado na programação, o público se reconhece e se sente incluído e representado pelos conteúdos exibidos. A tendência é que os telejornais invistam cada vez mais em alternativas que os aproximem da audiência, seja usando uma linguagem mais coloquial, incluindo formatos que se diferem das notícias e reportagens factuais. Há também o fortalecimento dos telejornais regionais, uma oportunidade para que as pessoas se identifiquem com os conteúdos que são exibidos na TV e, assim, tornar-se mais próximas e participativas (COUTINHO, 2009). Uma das maneiras de fazer isso, como dito anteriormente, é adaptando a linguagem, gêneros e formatos.

A chegada das mídias digitais fez com que os meios de comunicação mais tradicionais passassem por uma série de transformações em suas rotinas produtivas. Com isso, os telejornais foram, ao longo dos anos, absorvendo características de outros gêneros para adaptar-se às demandas da audiência, agora, ainda mais exigente e interativa. Esse processo de "absorção" de outros gêneros é chamado de hibridização. No decorrer dos anos, a classificação e a análise dos gêneros passaram por mudanças (BELÉM, 2017), dentre elas, a implantação de conteúdos com características de entretenimento junto à informação, fenômeno classificado pela literatura como infotenimento (DEJAVITE, 2006; GOMES, 2009).

O papel de "divertir", do jornalismo, tem recebido várias denominações: jornalismo diversional, cultural e de entretenimento e, por último, infotenimento. O termo infotenimento é um "neologismo que traduz o 
entrelaçamento de fronteiras entre a informação e o entretenimento" (GOMES, 2009, p. 195). Trata-se, então, de um jornalismo que oferece serviço ao telespectador e, ao mesmo tempo, tem implícito um caráter de divertimento. De acordo com Gutmann, Santos e Gomes (2009), o infotenimento é consequência da busca por melhores números de audiência dos meios de comunicação, ou seja, é uma "estratégia de captura de audiência, sendo essas estratégias o que normalmente se considera como entretenimento" (GUTMANN; SANTOS; GOMES, 2009, p. 76). Os autores sugerem que a distinção entre informação e entretenimento está perdendo força como princípio organizador do campo midiático.

Os conteúdos do infotenimento são considerados notícias light, porque "esses tipos de conteúdo satisfazem nossas curiosidades, estimulam nossas aspirações, possibilitam extravasar nossas frustrações e nutrem nossa imaginação" (DEJAVITE, 2007, p. 3). Neste trabalho, partimos dessa discussão que Dejavite (2007) faz sobre o jornal impresso e a adaptamos para a televisão, mais especificamente para os quadros televisivos. Assim, defendemos que o infotenimento possa ocorrer a partir da forma e do conteúdo, mas não se caracterizando como um sinônimo de notícias leves. Isso porque entendemos que as "notícias duras" e "notícias leves" estão ligadas à natureza do fato (TUCHMAN, 1978), e não ao tratamento dado a ele - o que seria caracterizado pelo infotenimento. Notícias de política, por exemplo, que são de natureza hard, podem ser abordadas a partir de uma perspectiva do infotenimento, como outros estudos já mostraram, tanto olhando para objetos televisivos (GUTMANN, 2008; MUNDIM, 2010), quanto de audiovisual veiculado no Youtube (BERROCAL; DOMÍNGUEZ; GARCÍA, 2012).

O infotenimento, portanto, é uma alternativa para os telejornais se adaptarem aos novos contextos e exigências do público, produzindo conteúdos capazes de distrair e informar ao mesmo tempo (DEJAVITE, 2006; BELÉM, 2015). Isso, como discutido acima, vai além da própria natureza do acontecimento. Com isso, Dejavite (2006, p. 68), ao analisar o fenômeno na perspectiva dos jornais impressos, afirma que o público "exige que a notícia informe, distraia e também Ihe traga uma formação sobre o assunto publicado", pois se as informações não cumprirem esse papel, não vão chamar a atenção da audiência. Isso é importante, segundo Belém (2015), que desenvolve o trabalho olhando para a noticiários exibidos na televisão, especialmente porque o público se encontra disperso em meio às novas tecnologias, por isso "[...] o conteúdo 
dos telejornais precisa ser mais atrativo, capaz de distrair e, ao mesmo tempo, informar. Mesclam-se categorias e gêneros; as estratégias se multiplicam e redefinem perfis editoriais" (BELÉM, 2015, p. 10).

O processo de hibridização e surgimento do infotenimento surgiu da necessidade de adaptação às novas necessidades da audiência e se relaciona diretamente aos conteúdos dos quadros analisados neste trabalho. Parte dessas formas de compor o telejornal, os quadros não faziam parte dos noticiários até meados da década de 1970, quando passaram a ser incorporados na programação, inicialmente no Jornal Hoje. Estas reportagens, caracterizadas por uma linguagem leve, interpelações e interações entre apresentadores, repórteres e o público, além do uso de fontes especialistas para darem respaldo aos temas abordados, demonstram a necessidade de os noticiários se adaptarem aos novos contextos do público, produzindo conteúdos leves, numa tentativa de quebrar o fluxo de hard news ${ }^{4}$ presente na maior parte do tempo dos noticiários ${ }^{5}$.

Outro ponto a ser destacado neste trabalho é que o infotenimento e as soft news ${ }^{6}$, apesar de conceituações próximas e complementares, apresentam algumas distinções. As soft news são compreendidas como assuntos relacionados originalmente ao entretenimento, enquanto no infotenimento é possível trabalhar com temáticas de diferentes naturezas - como política, conforme argumentado anteriormente. A definição deste tipo de jornalismo vai além e está relacionada ao processo de construção de uma matéria atraente ao telespectador com a utilização de uma série de estratégias, como a abordagem, a linguagem, os recursos visuais e sonoros - tudo isso aliado à tentativa de preservar algumas premissas básicas do jornalismo, como a credibilidade, relevância e o interesse público.

Tratando especificamente dos quadros televisivos, Cajazeira (2011, p. 26) defende a ideia de que "os quadros [...] são formas de fidelização

\footnotetext{
4 Para Gaye Tuchman (1978), hard news são conteúdos mais objetivos. São matérias consideradas mais sérias, como as das editorias de política, economia e segurança, por exemplo. No entanto, a autora se refere à natureza do fato, e não especificamente ao seu modo de tratamento. Por isso, defendemos que é possível tratar de assuntos de natureza hard a partir da perspectiva do infotenimento.

5 Reconhecemos que há infotenimento tanto em assuntos com temáticas hard news, como saúde e economia, quanto em matérias soft news, com narrativas que aproximam repórter, personagem e público. Tais efeitos de espontaneidade e proximidade são alcançados com a construção de um texto menos formal, o uso de recursos 6 Para Shoemaker e Cohen (2006), as soft news são "geralmente baseadas em eventos não programados. O repórter ou a organização de mídia não está sob pressão para publicar as notícias em uma determinada data ou hora- as notícias leves não precisam ser oportunas" (tradução nossa).
} 
do público, já que criam vínculos de credibilidade com a informação", bem como tendem a ter narrativas mais fluidas, como uma tentativa de quebra do fluxo de notícias hard com o objetivo de levar informações e aproximar a audiência por meio de conteúdos e linguagens leves - características que os enquadra como de infotenimento. Ainda conforme o autor, os quadros são espaços fixos considerados como um recurso para arrematar a audiência de um programa e uma forma de preencher o espaço do tempo com mais ritmo na condução da narrativa do telejornal.

Escolhemos os quadros como objeto de análise deste trabalho por considerarmos um espaço "fértil" para o infotenimento ser trabalhado. Tal fato se baseia em vários aspectos, dentre eles uma linguagem leve, mais fácil de ser consumida, característica dos programas televisivos de modo geral, a produção diversificada e aprofundada dos conteúdos, o tempo de veiculação maior que o das matérias factuais e a possibilidade de utilizar fontes diversificadas. Assim, os quadros possibilitam que temas cotidianos sejam trabalhados de uma maneira diferente da abordada em uma notícia, por exemplo, como veremos a seguir. Antes, apresentamos brevemente o espaço dos quadros na programação do principal telejornal do estado do Maranhão.

\section{O JMTV $1^{\text {a }}$ Edição e os quadros fixos}

O JMTV $1^{a}$ Edição, telejornal da afiliada da Rede Globo no Maranhão - TV Mirante, é exibido em todo o estado. O noticiário é veiculado ao meio dia, de segunda a sábado, com duração média de 40 minutos, e é composto pelas matérias factuais sobre os acontecimentos das cidades maranhenses. Em seu site, o noticiário é definido como um canal direto do telespectador com o poder público na busca de solução para os problemas, "um jornalismo que tem a parceria da comunidade e que destaca os problemas diários enfrentados pela população maranhense" (REDE GLOBO, s/d).

Além das matérias factuais, o telejornal conta ainda com três quadros fixos - Vida Saudável, Fica a Dica e Meu Bebê, objetos empíricos deste trabalho - que abordam temas relacionados à saúde, comportamento, educação, esporte, dentre outros. O quadro Fica a Dica, começou a ser veiculado no dia 8 de maio de 2014 e surgiu com a 
proposta de mostrar dicas de culinária à população maranhense, mas posteriormente passou a abordar temas como moda, comportamento, cuidados com o corpo e dicas de lazer. Ele é exibido, regularmente, todas às terças-feiras.

Já o quadro Vida Saudável, exibido às segundas-feiras, iniciou em 6 de abril de 2015 com a proposta de veicular reportagens sobre boa alimentação e práticas de atividades físicas. Um mês depois da estreia do Vida Saudável, no dia 6 de maio de 2015, foi ao ar a primeira edição do quadro Meu Bebê, que tem o objetivo de mostrar como lidar com a saúde, a educação e o comportamentos das crianças. O quadro vai ao ar todas às quartas-feiras.

As reportagens destes quadros são caracterizadas por uma linguagem leve, interpelações e interações entre apresentadores, repórteres e público. Observa-se ainda o uso de fontes especialistas para dar respaldo aos temas abordados. Para a construção desta pesquisa, defendemos que os quadros telejornalísticos são estratégias de narrativas mais fluidas e fazem parte das alterações feitas ao longo dos anos com o objetivo de levar informações e aproximar a audiência por meio de conteúdos e linguagens leves. Assim, o presente trabalho se propõe a identificar qual a função dos quadros no telejornal JMTV $1^{a}$ Edição, bem como verificar como o infotenimento se apresenta nesses espaços, como veremos a seguir.

\section{Procedimentos metodológicos}

Para a realização desta pesquisa foi utilizado o método de pesquisa bibliográfica, para fazer um apanhado na literatura sobre os temas discutidos neste trabalho e, em seguida, a Análise de Conteúdo quantitativa, proposta por Bardin (2006). A análise e coleta de dados desta pesquisa foram baseadas nos quadros fixos telejornal JMTV $1^{a}$ Edição - Vida Saudável, Meu Bebê e Fica a Dica -, produzidos nas cidades de Imperatriz e São Luís e transmitidos para todo o estado do Maranhão, pela TV Mirante. A escolha do JMTV $1^{\text {a }}$ Edição se deu por ele ser o telejornal de maior audiência na região, com um total de 58\% do público; a segunda emissora possui $26 \%$ de audiência, de acordo com o Atlas de 
Cobertura da TV Mirante ${ }^{7}$. O telejornal da emissora é transmitido para mais de 48 municípios do estado. Assim, foram assistidas 151 reportagens dos quadros fixos do JMTV $1^{a}$ Edição por meio da plataforma do telejornal no G1 Maranhão, da Rede Globo.

O processo de escolha do corpus da pesquisa consiste na observação sistematizada de 151 reportagens veiculadas no noticiário durante todo o ano de 2018. O primeiro passo para a análise consistiu em assistir e catalogar todas as reportagens transmitidas durante o período de observação, verificando quais delas apresentavam características do infotenimento. Na produção dos telejornais, o infotenimento pode se apresentar de diversas maneiras, por isso, para o desenvolvimento da pesquisa, foi elaborado um livro de códigos a partir da metodologia utilizada pelo extinto Grupo de Estudos em Convergências e Narrativas Audiovisuais da Universidade Federal do Maranhão (UFMA), que, anteriormente, desenvolveu a pesquisa "Entretenimento com a informação no telejornalismo local: um estudo de caso sobre o JMTV $1^{a}$ edição" (MEDEIROS, BELÉM, ALENCAR, 2019) ${ }^{9}$, com a proposta do trabalho de observar a presença do infotenimento ao longo de cinco edições completas do no telejornal JMTV $1^{\text {a }}$ edição, o que totalizou a análise de 41 reportagens do telejornal no período compreendido entre 26 de fevereiro a 2 de março de 2018. Algumas categorias foram ajustadas de acordo com as necessidades percebidas durante o período que antecedeu a coleta teste, para balizar a análise de conteúdo, compreendendo as seguintes variáveis: quantidade de personagens, presença de especialistas, temática, linguagem, condução e técnica.

Com relação à variável Temática foram consideradas 11 das 32 possibilidades apresentadas por Dejavite (2006) para identificar a presença da temática predominante de infotenimento nas reportagens, são elas: Beleza, notícias sobre os cuidados com o corpo, dieta, maquiagem, cabelo, plástica e etc.; Casa e decoração, matérias sobre moradia; Comportamento, matérias referentes às atitudes e reações de um indivíduo no meio social; Consumo, notícias que acompanham a aplicação das riquezas e dos desejos econômicos do espectador. Cultura, assuntos como patrimônios e historicidades; Eventos, são notícias que

7 O Atlas de Cobertura da TV Mirante é um documento interno da emissora e foi disponibilizado à autora por meio de um produtor do telejornal.

8 Disponível em: http://g1.globo.com/ma/maranhao/jmtv-1edicao/videos/. Acesso em: 10 ago. 2019.

9 Disponível em: http://rebej.abejor.org.br/index.php/rebej/article/view/317. Acesso em: 12 de jan. 2021. 
divulgam a realização ou andamento de algum evento; Esportes, matérias ligadas a qualquer tipo de prática esportiva; Formação pessoal, assuntos relacionados ao empreendedorismo; Gastronomia, matérias que englobam assuntos com alimentos e culinária; Moda, referente estilo de roupas e acessórios; Turismo/Lazer/Hotelaria, novidades sobre viagens, passeios e afins. As temáticas Saúde e Educação foram inseridas posteriormente ao percebemos um número elevado de reportagens com esses temas. Assim, categorizamos em Saúde matérias com temas relacionados à prevenção e o tratamento de doenças; Educação, matérias relacionadas ao estudo, alfabetização e preparação para provas.

$\mathrm{Na}$ variável Linguagem foram consideradas as categorias Texto Popular - uso de linguagem coloquial, adjetivos e/ou gírias; Narração Informal - descontração e informalidade na fala do apresentador/repórter; e o Discurso pessoal/Subjetivo - uso de pronomes possessivos e opiniões pessoais.

Em Condução consideramos a forma como o repórter conduziu a reportagem. A variável foi dividida em três categorias: Informalidade quando o repórter cria um efeito de espontaneidade durante a matéria; Centralidade na figura do apresentador/repórter - valorização da conversação entre apresentadores e repórteres; e, por último, Interpelação da audiência - onde se propõe a simular uma interação com o público, com imposições discursivas "venha", "assista", "acesse" e etc.

Por fim, na variável Técnica foram consideradas características na forma como o telejornal utilizou de recursos visuais (gráficos ou não) para compor a reportagem. As possibilidades de categorização são: Recursos inovadores de gravação - uso de câmeras aquáticas, câmeras 360 graus, drones; Efeitos visuais e/ou sonoros evidentes - edição na montagem das imagens de áudios, ou seja, efeitos de pós-produção; e Videografismo destacado - uso de tabelas, gráficos e animações para ilustrar as reportagens ${ }^{10}$.

\footnotetext{
10 Destacamos que a presença de videografismos, de forma isolada, não define que uma reportagem seja caracterizada como infotenimento, pois este recurso visual é característica primordial na linguagem televisiva. Neste sentido, o videografismo só foi determinante para a identificação do infotenimento nas matérias analisadas quando aliados a outras categorias ou características de análise presentes no livro de códigos. Ou seja, se os quadros apresentassem apenas recurso de videografismo e nenhuma outra característica de infotenimento, ele não seria considerado. No entanto, não houve nenhum caso dessa natureza no corpus analisado neste trabalho.
} 


\section{O infotenimento nos quadros do JMTV $1^{\text {a }}$ Edição}

Neste tópico apresentaremos a análise quantitativa dos dados sobre os quadros Vida Saudável, Fica a Dica e Meu Bebê relacionados à quantidade e duração das reportagens, bem como a presença de especialistas, as temáticas gerais, a linguagem, condução e técnica. Assim, descreveremos algumas cabeças ou off's para exemplificar como se apresenta a linguagem do telejornal, a condução e a técnica.

A Tabela 1, a seguir, apresenta o número de reportagens de cada quadro. Assim, podemos perceber que durante todo o ano de 2018, não há variação na quantidade de matérias veiculadas em cada quadro, visto que a periodicidade de todos eles, é semanal.

Tabela 1 - Quantidade de reportagens coletadas em cada quadro

\begin{tabular}{cc}
\hline Quadro & $\mathbf{N}^{\circ}$ de reportagens \\
\hline Vida Saudável & 49 \\
Fica a Dica & 51 \\
Meu Bebê & 51 \\
\hline Total & 151 \\
\hline
\end{tabular}

Fonte: Elaborado pelas autoras (2019).

Em relação ao tempo destinados pelo telejornal para cada um, percebemos que as matérias dos quadros ocuparam um espaço significativo na programação, com a média de 5 minutos e 34 segundos. Percebe-se que o tempo destinado ao infotenimento no JMTV é relevante quando levamos em consideração, por exemplo, o tempo destinado a uma notícia factual no Jornal Nacional, que varia entre 1 e 30 segundos a 3 minutos (OLIVEIRA, 2014). Nos quadros do JMTV, todas as matérias ultrapassam significativamente deste tempo, como é o caso da reportagem do quadro Meu Bebê, exibida no dia 10 de janeiro. A reportagem em questão foi exibida durante 7 minutos e 52 segundos - o que corresponde a $20 \%$ do telejornal, e falava sobre formas de promover uma alimentação saudável para as crianças. 
onforme aponta Duarte (2003), o espaço em televisão é muito caro. Assim, a produção televisiva opta por investir em conteúdos já tradicionais ou novos modelos híbridos de gêneros e formatos que agradem o público, como a informação e o entretenimento. Ao falar sobre o tempo no telejornal, Vizeu e Oliveira (2018) destacam que o tempo molda as escolhas noticiosas e serve de norte para o noticiário de forma geral, desde a produção do conteúdo até a exibição para o público.

O próximo dado diz respeito à presença de especialistas entre as fontes. Em 72,2\% das reportagens constatou-se a presença de pelo menos um especialista; já 16,6\% apresentavam dois profissionais e apenas em 1,3\% chegavam a contar com a presença de até quatro especialistas. Neste caso, consideramos fontes especialistas, ou especializadas, profissionais que analisam e oferecem informações complementares a respeito do tema abordado (SCHMITZ, 2011).

Gráfico 1 - Quantidade de especialistas presentes nos quadros

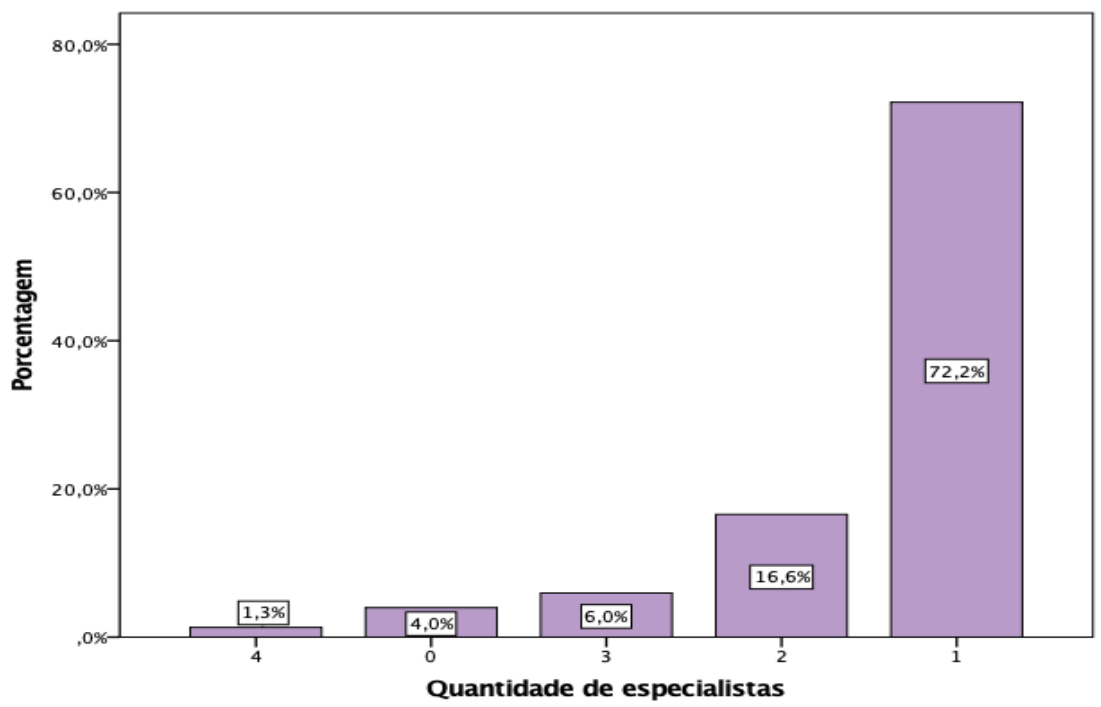

Fonte: Elaborado pelas autoras (2019).

Ao analisar a temática predominante em todos os quadros, destacam-se reportagens que abordam temas relacionados à Saúde (Gráfico 2). Ela foi tema de 56 das 151 reportagens analisadas, o equivalente a $37,1 \%$ dos quadros. Em seguida, a categoria Gastronomia destaca-se em 29 reportagens durante o ano de 2018, correspondendo a um 
percentual de 19,2\%. As reportagens com a temática Comportamento aparecem em 17 edições dos quadros, o que equivale a 11,3\% de todas as matérias analisadas. As três temáticas que mais se destacaram totalizam 103 do corpus analisado. As outras duas categorias que também merecem destaque são Beleza, com 11 reportagens (7,3\%), e Esportes, com 9 matérias (6\%).

Gráfico 2 - Temáticas predominantes nos quadros

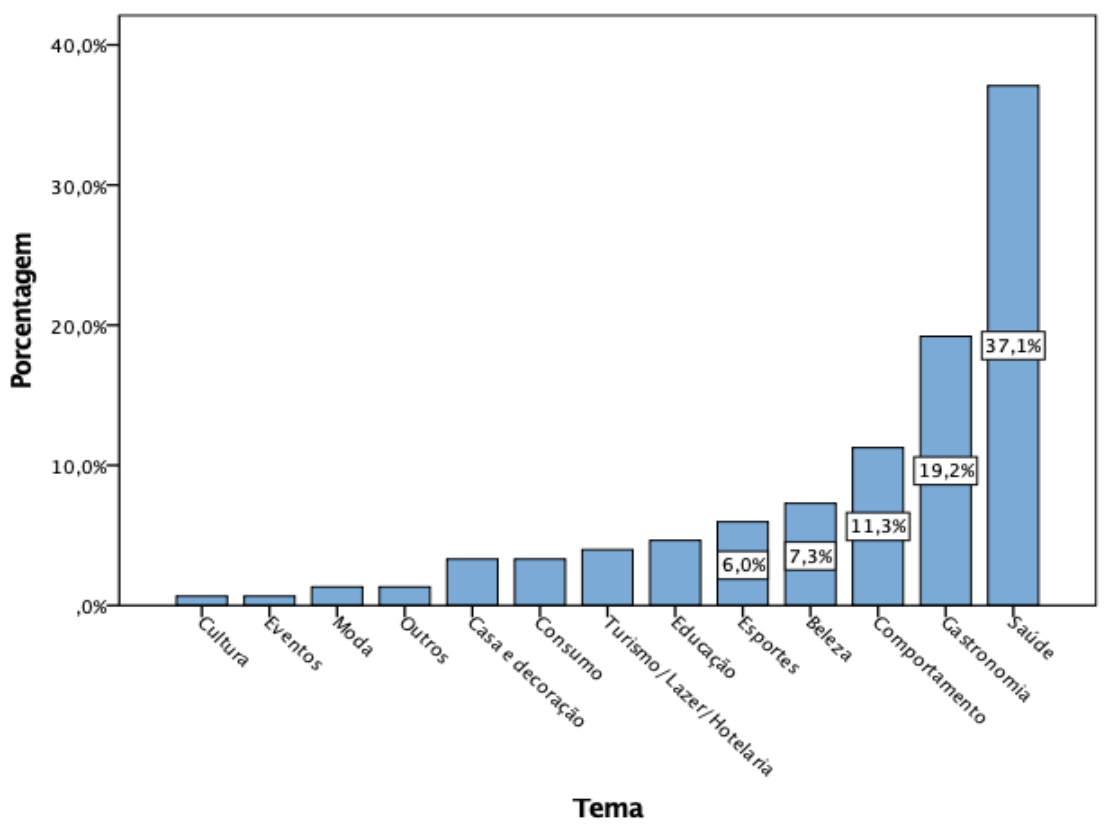

Fonte: Elaborado pelas autoras (2019).

Temáticas relacionadas à saúde, principalmente a respeito de prevenção de doenças e promoção de qualidade de vida, acabam ganhando destaque nos meios de comunicação. Para Robalinho (2014), o interesse dos noticiários pela saúde decorre graças aos avanços técnicos-científicos das últimas décadas, o que possibilitou aos indivíduos uma maior consciência sobre os cuidados com a saúde e as formas para viverem mais. Essas informações ressaltam o importante papel da mídia, como é o caso do JMTV $1^{\text {a }}$ Edição, não só em divulgar as mazelas da saúde pública e os problemas da saúde suplementar, mas também na promoção e prevenção de saúde. 
Na variável Linguagem, 141 reportagens apresentavam o Texto Popular (42,9\%), 129 matérias tinham Narração Informal (39,2\%) e 59 o Discurso Pessoal (17,9\%). A tabela abaixo mostra a frequência das categorias. É preciso ressaltar que o número total não fecha em 151 reportagens porque esta variável permitia marcar a presença de mais de uma dessas características e a maioria das matérias apresentava duas ou mais.

Tabela 2 - Linguagens mais frequentes nos quadros

\begin{tabular}{ccc}
\hline Linguagem & $\mathbf{N}^{\circ}$ de reportagens & Porcentagem \\
\hline Texto popular & 141 & $42,9 \%$ \\
Narração informal & 129 & $39,2 \%$ \\
Discurso pessoal & 59 & $17,9 \%$ \\
\hline Total & 329 & $100 \%$ \\
\hline
\end{tabular}

Fonte: Elaborado pelas autoras (2019).

Em relação à variável Condução, em 134 reportagens os repórteres ou apresentadores usaram recursos de Informalidade para criar um efeito de espontaneidade na matéria, o equivalente a 55,8\% dos casos. Além disso, a Centralidade na Figura do Repórter/Apresentador apareceu em 15 matérias, o que significa que, nessas ocasiões, houve o envolvimento dos jornalistas com a notícia, como, por exemplo, se colocar como um personagem. A Interpelação da Audiência também teve destaque em 91 reportagens e foi percebida por meio da simulação de uma interação com a audiência por meio de cumprimentos e imposições discursivas.

Na variável Técnica, apenas 2 reportagens apresentavam Recursos Inovadores, como o uso de drones, câmeras aquáticas e 360'. Em 145 casos, as reportagens apresentaram Efeitos visuais e/ou sonoros (63\%), como o uso de backgrounds e montagem de imagens - algo já tradicionalmente utilizado pelas narrativas televisivas, não só nos quadros. O Videografismo esteve presente em 83 matérias, e este recurso foi usado para ilustrar os assuntos, totalizando $36,1 \%$ das reportagens exibidas.

Nos próximos tópicos, analisaremos separadamente os dados e características de cada quadro do JMTV $1^{a}$ Edição. Iremos explicar os principais temas que apareceram durante análise. Além disso, serão apresentados, por meio de exemplos, quais recursos considerados de infotenimento aparecem nas variáveis linguagem, a condução e técnica. 


\subsection{0 infotenimento no quadro Vida Saudável}

Durante o período de observação, foram analisadas 49 edições do quadro Vida Saudável, exibidas no ano de 2018. Ao observar a presença de temas do infotenimento no Vida Saudável apenas 8 das 13 possibilidades apontadas por Dejavite (2006) foram encontradas (Gráfico 3). Assim, das 49 reportagens, 63,3\% tratavam de temáticas relacionadas à saúde, categoria em que consideramos as matérias com temas relacionados à prevenção e o tratamento de doenças e cuidados com o corpo para a promoção do bem-estar.

Apesar de, inicialmente, saúde não ser considerada essencialmente uma editoria com matérias soft news, no JMTV isso acontece. Mais adiante, analisaremos como os recursos que consideramos como de infotenimento aparecem durante as pautas deste quadro.

Gráfico 3 - Temáticas específicas do quadro Vida Saudável

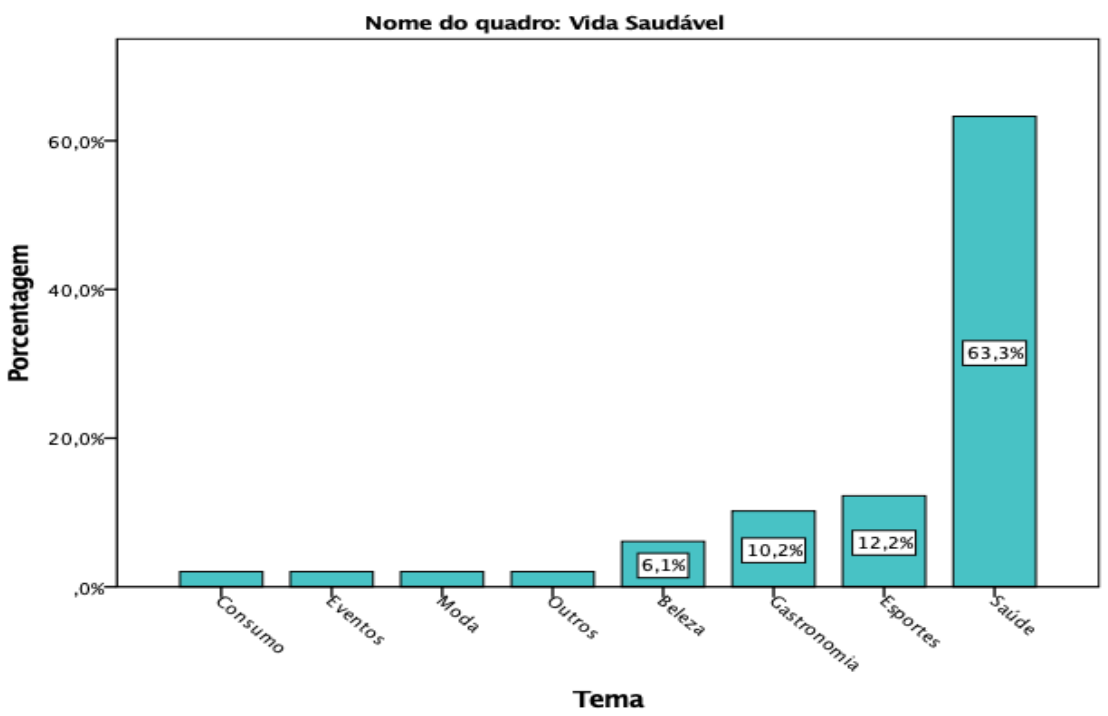

Fonte: Elaborado pelas autoras (2019).

Neste sentido, identificamos a reportagem exibida no dia 15 de janeiro com o título "Vida saudável: mudando a rotina na alimentação e garantindo novo estilo de vida". Na matéria, com 6 minutos e 16 segundos de duração, o uso de recursos visuais e/ou sonoros inovadores 
foi feito por meio de fotos do arquivo pessoal do personagem. A reportagem conta com a presença de dois especialistas para dar dicas e explicar formas de conseguir uma alimentação saudável. Além disso, na variável Linguagem encontramos a presença do texto popular e do discurso pessoal por parte do repórter.

Outras duas temáticas também apresentaram um percentual significativo no quadro, foram Esportes, com 12,2\% das reportagens, seguido de Gastronomia, com 10,2\%. Na temática de esporte, trazemos como exemplo a reportagem exibida no dia 5 de março com o título "Caminhada ou corrida? Qual modalidade se aplica melhor a você?". Assim como na anterior, a matéria, com 5 minutos de duração, também recorre aos BGs, trata o personagem pelo primeiro nome e conta com a presença de uma animação para ilustrar a reportagem. Pereira e Gomes (2012) destacam que as mensagens transmitidas por imagens facilitam a compressão mais do que as informações faladas. Segundo eles, essas imagens são mais eficazes ao comunicar o seu sentido e isso ocorre de forma mais rápida. Além disso, o repórter faz uso de texto leve e simula uma interação com o público.

$\mathrm{Na}$ categoria Gastronomia, selecionamos a reportagem do dia 7 de maio. A matéria durou 4 minutos e 7 segundos e foi a única produzida pela equipe de telejornalismo de Imperatriz durante o período de análise. Todas as outras reportagens foram produzidas pela equipe de São Luís. Com o título "Conheça a dieta Low Carb", a reportagem dá dicas de como emagrecer reduzindo o consumo de alimentos com carboidratos, e passa a receita de fazer um pão de frigideira. Em Linguagem, a matéria apresenta um texto leve e narração informal. O repórter começa falando a seguinte frase: "Já pensou em uma dieta que te dá a possibilidade de emagrecer duas vezes mais rápido?”. Com relação à Técnica, o uso de BGs e vidrografismos também é aparente.

\subsection{O infotenimento no quadro Fica a Dica}

No quadro Fica a Dica o tema de maior abordagem durante o ano de 2018 foi Gastronomia, seguido por dicas de Beleza e Saúde, conforme podemos verificar no Gráfico 4. 
Gráfico 4 - Temáticas específicas do quadro Fica a Dica

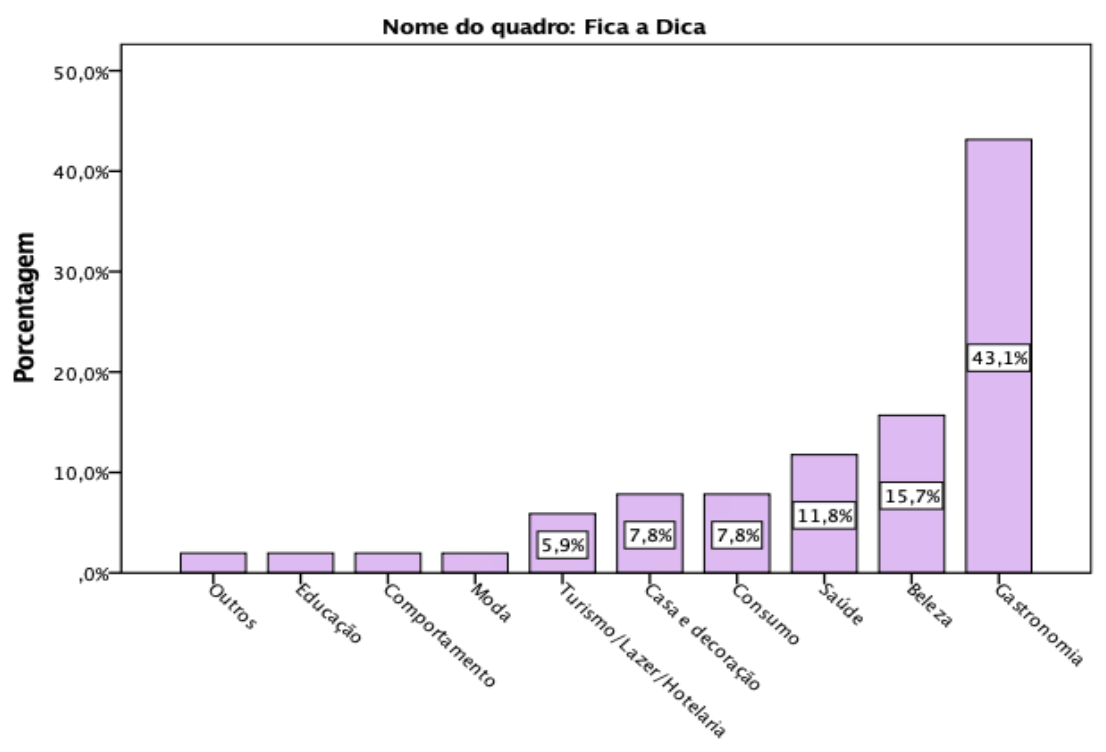

Tema

Fonte: Elaborado pelas autoras (2019).

A reportagem do dia 13 março apresentava o título "Veja como preparar um prato para a páscoa". Com relação ao tema de infotenimento predominante, consideramos Gastronomia. A matéria tem o texto leve, narração informal e discurso pessoal. A repórter torna-se personagem da matéria, o que fica bastante evidente pelo fato de a própria jornalista encerrar a reportagem experimentando o prato.

No dia 23 de janeiro, o JMTV exibiu a reportagem com o título "Descubra qual o segredo para sair bem na foto". A reportagem do quadro Fica a Dica está inserida na temática de Beleza. Com 5 minutos de duração, a matéria começa com fotos da repórter feitas em um ensaio fotográfico para a realização da matéria. Relacionando a matéria aos elementos do livro de códigos, identificamos a variável Centralidade na figura do apresentador/repórter, ao observarmos que a repórter se envolve e aparece como personagem da matéria em vários momentos. Além disso, observamos a presença do Discurso pessoal, Linguagem informal e Interpelação da audiência. 
Na categoria Saúde, temos a matéria do dia 16 de janeiro, com o título "Como organizar seu armário". A reportagem ensina truques para organizar o guarda-roupa. Assim como nas edições analisadas anteriormente, neste caso a repórter também ocupa o papel de personagem e se insere na matéria para aprender a organizar roupa. Além disso, a jornalista utiliza de um texto popular, discurso pessoal e interpelação da audiência, como por exemplo, ao finalizar a matéria com uma pergunta: "Ih, acho que vou arrumar meu guarda-roupa hoje e vocês aí de casa, topam o desafio?".

\subsection{O infotenimento no quadro Meu Bebê}

O terceiro e último quadro do JMTV $1^{a}$ Edição, o Meu Bebê teve como tema principal durante o ano de 2018 a saúde das crianças e adolescentes, seguido de reportagens sobre comportamento e educação (Gráfico 5).

Para exemplificar a primeira temática, selecionados o quadro Meu Bebê exibido no dia 10 de janeiro, intitulado "Conheça maneiras de promover uma alimentação saudável para as crianças", que tem como temática a saúde. O quadro contou com a presença de duas especialistas para dar respaldo à reportagem. Nas questões visuais, chama a atenção o uso de fotos da internet para ilustrar e videografismos em forma e lista de receitas saudáveis. Além disso, em relação à linguagem, a repórter constrói uma familiaridade com a fonte ao chamá-la por pronomes pessoais. 
Gráfico 5 - Principais temáticas do Meu Bebê

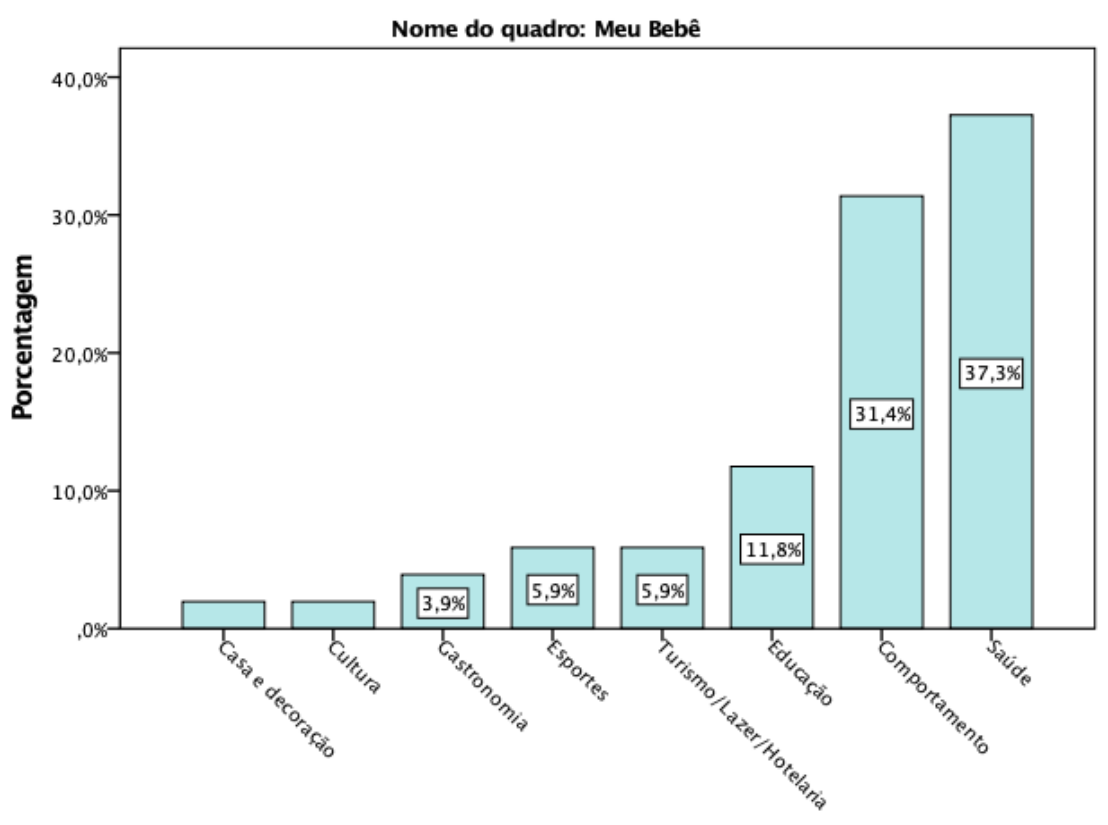

Tema

Fonte: Elaborado pelas autoras (2019).

A segunda reportagem selecionada para o quadro Meu Bebê, foi exibida no dia 7 de março. Com o título "Dicas que podem ajudar as crianças escreverem bem", a reportagem destacou a importância da leitura e de uma boa base escolar para a criança chegar no ensino médio preparado. A reportagem fez uma animação com a história do livro de uma fonte da matéria, o Arthur. A animação foi feita com a narração do autor de fundo, além da presença de BGs. Além disso, também foi identificada a variável Interpelação da audiência, já que a reportagem é construída de maneira afetiva e próxima dos personagens e do público. Outro fato que chamou a atenção durante a análise foi que o próprio personagem, o Arthur, narrou sua história durante a reportagem.

Neste trabalho analisamos como os recursos de infotenimento são usados durante os quadros fixos do JMTV $1^{a}$ Edição. A chamada notícia light, proposta por Dejavite (2006), surge como conteúdo informativo, mas também é capaz de distrair e trazer informações sobre os assuntos veiculados nos quadros, conforme os exemplos citados. O que se 
observa é que os quadros, embora tenham grandes temáticas pré-definidas - dicas sobre questões do dia a dia, vida de bebê/criança e saúde e bem estar -, trabalham com esses temas de maneira diversa, mais aprofundada, trazendo muitos personagens e especialistas para discuti-los. Trabalham, de fato, a informação de serviço com a roupagem do entretenimento. Esse ponto e os outros achados deste trabalho serão apresentados a seguir, nas conclusões.

\section{Considerações finais}

Este trabalho se propôs a compreender de que forma o infotenimento está presente nos quadros fixos do JMTV $1^{a}$ Edição. O infotenimento trata-se, portanto, de um jornalismo que oferece serviço ao telespectador e, ao mesmo tempo, tem implícito um caráter de divertimento, absorvendo características de outros gêneros para adaptar-se às demandas da audiência, agora, ainda mais exigente e interativa.

O entrelaçamento das fronteiras entre informação e entretenimento permite concluir que, nos quadros do JMTV, as matérias com temáticas hard podem ser trabalhadas a partir de elementos próprios do entretenimento. Deste modo, a análise dos dados possibilitou identificar que a maioria das reportagens exibidas nos três quadros o telejornal - Fica a Dica; Vida Saudável e Meu Bebê - abordava assuntos relacionados à saúde: pouco mais de 1/3 das matérias, o que equivale a 56 das 151 reportagens analisadas.

Apesar de, inicialmente, reportagens sobre saúde não apresentarem a intenção de entreter, no JMTV estes conteúdos são veiculados com elementos que permitem que as informações sejam remodeladas por um tom de leveza, como o uso de gráficos, animações, trilhas, além da linguagem com texto popular e narração informal. Assim, as reportagens são transformadas em conteúdos com elementos que prendem e entretêm os telespectadores, mas preservando o princípio de levar informação com o respaldo de especialistas.

O telejornal experimenta uma linguagem ainda mais leve e informal para transmitir as informações. Os apresentadores e repórteres estão cada vez mais no centro das matérias, buscando aproximar-se ainda mais do telespectador. Há um diálogo simulado entre jornalista e público 
por meio de perguntas e interpelações. O uso de elementos para tornar a linguagem leve foi o fator primordial percebido em todas as 151 reportagens analisadas. A variável "texto popular" de destaca estando presente em 141 matérias, seguida da narração informal e do discurso pessoal.

Em relação à condução, a informalidade é a categoria mais presente nas reportagens. A relação de familiaridade criada pelos jornalistas com os personagens é um fator que chama a atenção, visto que, em todas as matérias a intenção era nitidamente provocar efeito de espontaneidade e proximidade entre repórter, personagem e público. Os recursos técnicos também se destacam nas reportagens, principalmente os backgrounds e videografismos, como animações. Estes elementos são utilizados para dar fluidez e enriquecer os conteúdos. Além disso, estes artifícios vão além do objetivo de entreter - eles tornam as reportagens didaticamente compreensíveis, para facilitar o entendimento, por meio de imagens, gráficos e tabelas.

A relação entre o entretenimento e a informação envolve uma ampla discussão no telejornalismo. Para alguns, é vista como um espaço de privilégio para o desenvolvimento e discussões de pautas mais aprofundadas e de maneira leve, no entanto, para outros jornalistas, o infotenimento ainda é visto com certo "preconceito", por considerarem que, de certa maneira, o entretenimento desacredita a informação. Por fim, espera-se que este trabalho colabore com a discussão a respeito do infotenimento, sobretudo na televisão, e que possibilite a realização de outras pesquisas na mesma perspectiva, com o objetivo de identificar as diversas mudanças que o esse fenômeno provoca na estrutura do telejornal. Além disso, ressalta-se que esta é uma pesquisa inicial que tem o objetivo de ser ampliada através de outros olhares em trabalhos futuros.

\section{REFERÊNCIAS}

BARDIN, Laurence. Análise de conteúdo. Lisboa: Edições 70, 2006.

BECKER, Beatriz. Televisão e telejornalismo: transições. 1.ed. São Paulo: Estação das Letras e Cores, 2016.

BELÉM, Vitor. Telejornalismo em transição: Reconfigurações da informação e apelo popular na notícia. Tese de doutorado apresentada na Pontifícia Universidade Católica de São Paulo, São Paulo, 2017. 
Quando a informação (con)funde-se com o entretenimento: a hibridização de gêneros no telejornal. XXXVIII Congresso Brasileiro de Ciências da Comunicação, Rio de Janeiro, 2015. Disponível em: http://portalintercom.org.br/anais/nacional2015/resumos/R10-2648-1.pdf. Acesso em: 17 out. 2019.

BERROCAL, S; DOMÍNGUEZ, E; GARCÍA, Marta. El "infoentretenimiento" político en Internet: La presencia de cinco líderes europeos em YouTube. RIPS, [s. I.], v. 11, ed. 4, p. 107-131, 2012.

CAJAZEIRA, Paulo. 0 jornalismo colaborativo no telejornal com as novas mídias digitais. Tese apresentada ao programa de Pós-Graduação em Comunicação e Semiótica da Pontifícia Universidade Católica de São Paulo. São Paulo, 2011.

DEJAVITE, Fábia. INFOtenimento: Informação + entretenimento no jornalismo. São Paulo: Paulinas, 2006.

A Notícia light e o jornalismo de infotenimento. XXX Congresso Brasileiro de Ciências da Comunicação. Santos: SP, 2007.

GOMES, Itania. O Infotainment e a Cultura Televisiva. In: João Freire Filho (org.). A TV em transição. Tendências de programação no Brasil e no mundo. 1 ed. Porto Alegre: Sulina, 2009.

GUTMANN, J. Aspectos audiovisuais do infotainment: o CQC como propósito de análise. In: Colóquio Internacional Televisão e Realidade. Anais de evento. Salvador, 2008.

GUTMANN, Juliana. SANTOS, Thiago. GOMES, Itania. Eles estão à solta, mas nós estamos correndo atrás: Jornalismo e entretenimento no Custe o Que Custar. In: Itania Maria Mota Gomes (org.). Televisão e realidade. Salvador: EDUFBA, 2009.

MUNDIM, Pedro. As consequências políticas do jornalismo de entretenimento. Líbero, XIII (25), p. 131-142, 2010

PEREIRA, Fábio. El mundo de los periodistas: aspectos teóricos y metodológicos. Comunicación y Sociedade. Guadalajara, v. 13, 2010, p. 101-124.

PEREIRA, Renato; GOMES, Rogério. O design no videografismo como ferramenta na construção de sentido. Revista Científica de Design, v.3, n. 1, 2012.

SCHMITZ, Aldo. Classificação das fontes de notícias. BOCC - Biblioteca Online de Ciências da Comunicação, 2011. Disponível em: http://www.bocc.ubi.pt/pag/schmitzaldo-classificacao-das-fontes-de-noticias.pdf. Acesso em: 18 de out. 2019

SILVA, Liliane. Infotenimento no telejornalismo no cenário da convergência midiática: Uma análise do Jornal Nacional. 2014. 87 f. Monografia apresentada ao curso de comunicação social da Universidade Federal de Juiz de Fora. Juiz de Fora, 2014. Disponível em: http://www.ufff.br/facom/ files/2014/03/Monografia-final-LilianeOliveira.pdf. Acesso em: 17 out. 2019.

SOUZA, Florentina; PIVETA, Patrícia. A evolução tecnológica na edição do telejornalismo. FAMECoS: mídia, cultura e tecnologia, Porto Alegre, v. 18, n. 2, p. 431-445, maio/ago. 2011. Disponível em: http://revistaseletronicas.pucrs.br/ojs/index.php/revistafamecos/article/view/9468. Acesso em: 17 out. 2019.

TUCHMAN, Gay. Making News: A Study in the Construction of Reality. New York: Free Press, 1978. 
VIZEU, Alfredo; CORREIA, João. A construção do real no telejornalismo: do lugar de segurança ao lugar de referência.In: VIZEU, Alfredo (org.). A sociedade do telejornalismo. Petrópolis, RJ: Vozes, 2008.

VIZEU, Alfredo; OLIVEIRA, Elane. Quanto tempo tenho? Aplicações da dialética na compreensão do tempo no telejornalismo. Joinville, 2018.

Recebido em: 21/04/20

Aprovado em: 27/01/21 


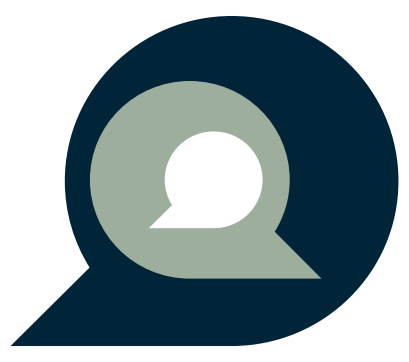

